\title{
Optimization of Sheet Metal Thickness and Die Clearance of Progressive Press Tool Using Finite Element Analysis and Artificial Neural Network Technique
}

\author{
Asif Nizam ${ }^{1}$, Morrish Kumar', Man Mohan Soni ${ }^{3}$ \\ ${ }^{1,2,3}$ Christian College of Engineering \& Technology, Bhilai, Chhattisgarh, India
}

\begin{abstract}
A progressive die performs a series of fundamental sheet-metal operations at two or more stations during each press stroke in order to develop a work piece as the strip stock moves through the die. Progressive die components are modeled in SOLID WORKS with selected dimensions for selected tool component. The main advantage of computer-aided progressive die design and machining is ability to build precision tooling in less time and at a lower cost. In this project main steps are Design and FEA analysis. This design is the optimal design. By using this design we can produce accurate components. This project basically focus on optimization of thickness and die clearance for a given range of cutting forces in order to minimize the stresses produced in die plate block which will lead to lesser deformation on the plate which will further lead to accurate sheet metal components produced by the progressive press tool. The optimized design parameters will be validated using remodeled components in ANSYS Software and further also compared with theoretically calculated design parameters.
\end{abstract}

Keywords: Press Tool, Sheet Metal Thickness, Die Clearance, Artificial Neural Network.

\section{Introduction}

Progressive tool performs two or more operations at different stages in each stroke. The stock strip is advanced through a series of stations that form one or more distinct press working operations on the strip to get the component [1].A progressive or follow on die has a series of operations. At section of the metal in which a hole had been pierced at a previous station. Thus after the first stroke, when only a hole will be punched, each stroke of the press produces a finished washer [4].

\subsection{Die Plate of Progressive Press Tool}

A die block is defined as the block or plate from which the die profile is cut. It is usually lower member of the tool. It provides cutting edge. The die opening has different designs and the design is selected after looking in the requirements and facilities available [1].

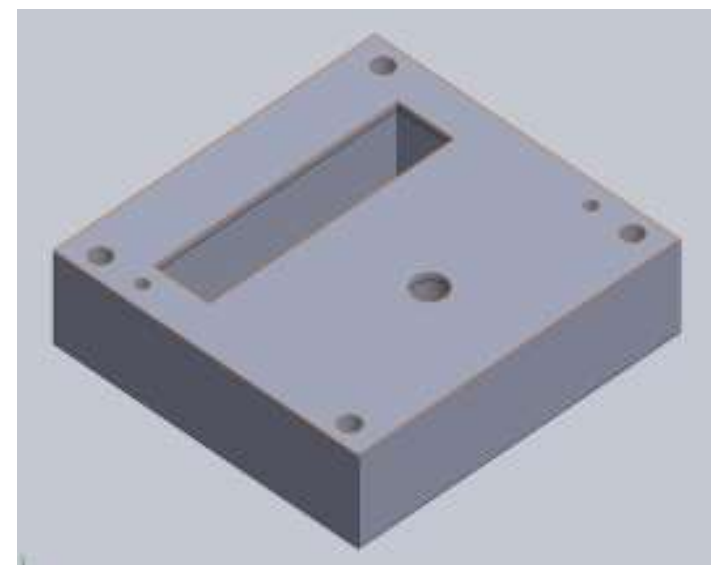

Figure 1: Die Plate of progressive press tool

\section{Cutting Clearance}

Cutting clearance is the gap between a side of the punch and the corresponding side of the die opening when the punch is entered into the die opening. Cutting clearance should always be expressed as the amount of clearance per side. Proper cutting clearance is necessary for the longer life of the tool. Quality of the piece part also depends on proper cutting clearance. A visual examination of the punched components will indicate the amount of clearance and whether the punch and die have optimum cutting clearance or excessive clearance or misalignment.

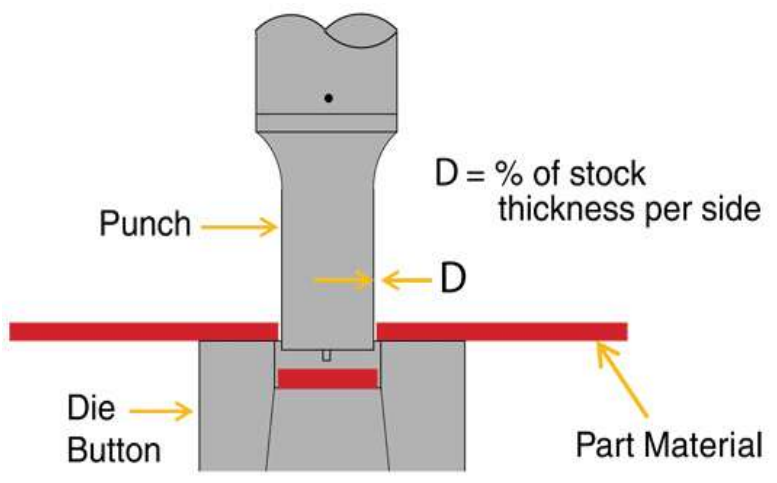

Figure 2: Cutting Die Clearances

\subsection{Clearance Equation}

The ideal clearance can be calculated using the following formula

Clearance $=\mathrm{C} * \mathrm{t} * \sqrt{\frac{T_{\max }}{10}}$

Where, $\mathrm{C}=0.005$ (accurate components) 


\section{International Journal of Science and Research (IJSR) \\ ISSN (Online): 2319-7064}

Index Copernicus Value (2013): 6.14 | Impact Factor (2014): 5.611

$=0.01$ (normal components)

$\mathrm{t}=$ sheet thickness in $\mathrm{mm}$

$\mathrm{T} \max =$ shear strength of stock material in $\mathrm{N} / \mathrm{mm} 2$

\section{Problems in Progressive Tool}

Based on my research and industrial survey, sheet metal components produced in the press tool in some particular cases are not found to be in perfect shape. Manufacturers as well as consumers often complain about slight amount of bend formation on final component produced.

For problem identification to some extent it was found that the problem is directly linked to bends observed in the die plate block. The bend in the die plate is caused due to non uniform application of force. The direction of punch travel should always be perpendicular to the direction of die plate face in order to have uniform application of force on the sheet metal.

Stress formation is the primary cause of deformation produced in any component. Due to stress produced in die plate block, deformations are caused which leaves an impression on die plate and creates gap between stripper plates and die plate. Due to which sheet metal strip will misalign. Shearing processes therefore will not produce required contours on component. Also a slight bend is observed on final sheet metal component. The problem identified therefore is stress produced in the die plate which is the main reason behind the production of non accurate components.

\section{Aim of Analysis}

The rectification of problem as mentioned above in the problem identification part deals with minimizing the stress produced in the die plate component of press tool. Based on the literature review related to the project topic, there are several factors which contribute to minimize the stress produced in the press tool component.

Out of these several factors, die cutting clearance and thickness of sheet metal component is considered for project study. Although other factors also play a very important role in minimizing the stress produced, but aim of study deals with optimization of above mentioned factors in rectifying the problem identified.

\section{Cutting Force Calculation}

Sheet thickness, $\mathrm{t}=1.5 \mathrm{~mm}$

Material, M.S (Component)

Shear Strength, $\eta=360 \mathrm{~N} / \mathrm{mm} 2$

Perimeter of component, $\mathrm{P}=215.28 \mathrm{~mm}$

Cutting Force, $\mathrm{F}=\eta * \mathrm{P} * \mathrm{~T}$

$=116251.2 \mathrm{~N}$

Safety Factor $=$ F $*$ F.O.S

$=116251.2 * 1.2$

$=139501.44 \mathrm{~N}$

$=(139501.44 / 9.81) \mathrm{Kg}$

Weight of Component $=14220.33 \mathrm{Kg}$
Weight of Component $=14.22$ TONNES

\subsection{Die Clearance Calculation}

\author{
Clearance per side $=\mathrm{C} * \mathrm{t} * \sqrt{ }(\eta \max / 10)$ \\ Where $\mathrm{C}=$ constant \\ $\mathrm{C}=0.005$ (very accurate component) \\ $\mathrm{C}=0.01$ (normal component) \\ $\mathrm{t}=$ sheet thickness $=1.5 \mathrm{~mm}$ \\ Clearance per side $=0.01 * 1.5 * \sqrt{ }(360 / 10)$ \\ Clearance per side $=0.09 \mathrm{~mm}$ per side
}

\subsection{Plate thickness Calculation}

Thickness of Die Plate, $t_{d}={ }^{3} \sqrt{F s}$

Where Fs $=$ Shear Force in Tones

$\mathrm{t}_{\mathrm{d}}=2.422 \mathrm{~cm}$

$\mathrm{t}_{\mathrm{d}}=24.22 \mathrm{~mm}$

Thickness of Punch Holder Plate, $=0.5 * \mathrm{t}_{\mathrm{d}}$

Thickness of Punch Holder Plate $=12.11 \mathrm{~mm}$

Thickness of Stripper Plate, $=0.75 * t_{d}$

$=18.165 \mathrm{~mm}$

Thickness of Bottom Plate, $=2 * \mathrm{t}_{\mathrm{d}}$

$=48.44 \mathrm{~mm}$

Thickness of Top Plate, $=1.5 *$ td

$=36.33 \mathrm{~mm}$

\subsection{Theoretical Stress Strain and Deformation for Die Plate Block (High Carbon High Chromium Steel)}

Die plate is considered as a fixed supported beam and therefore,

DEFLECTION, $\delta=\left(\mathrm{F} \mathrm{L}^{3}\right) /(192 \mathrm{EI})$

Where,

$\mathrm{F}=80 \%$ of the Cutting Force

$\mathrm{F}=($ Shearing Strength Factor $*$ Cutting Force $)$

$\mathrm{F}=93000.96 \mathrm{~N}$

SHEARING STRENGTH FACTOR $=\mathrm{C}_{\mathrm{s}}=0.8$

$\mathrm{L}=$ Length of the die plate $=110 \mathrm{~mm}($ Refer HASCO

CATALOG)

$\mathrm{E}=$ Young's Modulus of elasticity $=2 * 10^{\wedge} 5 \mathrm{~N} / \mathrm{mm} 2$

$\mathrm{I}=$ Moment of Inertia $=\left(\mathrm{b} * \mathrm{~h}^{3}\right) / 12$

$\mathrm{b}=$ Width of Die plate $=116 \mathrm{~mm}$ (Refer HASCO CATALOG)

$\mathrm{h}=\mathrm{t}=$ thickness of Die plate $=25 \mathrm{~mm}$ (Refer HASCO CATALOG)

$\mathrm{I}=\left(\mathrm{bh}^{3}\right) / 12=\left(116^{*} 50^{3}\right) / 12=151041.67 \mathrm{~mm} 4$

Deflection, $\delta=\left(93000.96 * 110^{3}\right) /(192 * 2 * 105 *$

151041.67)

$\delta=0.02134 \mathrm{~mm}$

Stress, $\zeta=\mathrm{F} / \mathrm{A}=(80 \%$ of cutting force $) /$ (cross sectional area of Die set)

$\zeta=(93000.96) /(110 * 116)$

$\zeta=7.2884 \mathrm{~N} / \mathrm{mm} 2$

Strain, $\varepsilon=$ deflection / length of Die plate

$\varepsilon=0.02032 / 110$

$\varepsilon=1.94 * 10^{-4}$ 


\section{International Journal of Science and Research (IJSR) \\ ISSN (Online): 2319-7064}

Index Copernicus Value (2013): 6.14 | Impact Factor (2014): 5.611

\section{Cad Modeling}

Computer-aided design (CAD) is the use of computer systems to aid in the creation, modification, analysis, or optimization of a design. CAD software is used to increase the productivity of the designer, improve the quality of design, improve communications through documentation, and to create a database for manufacturing.

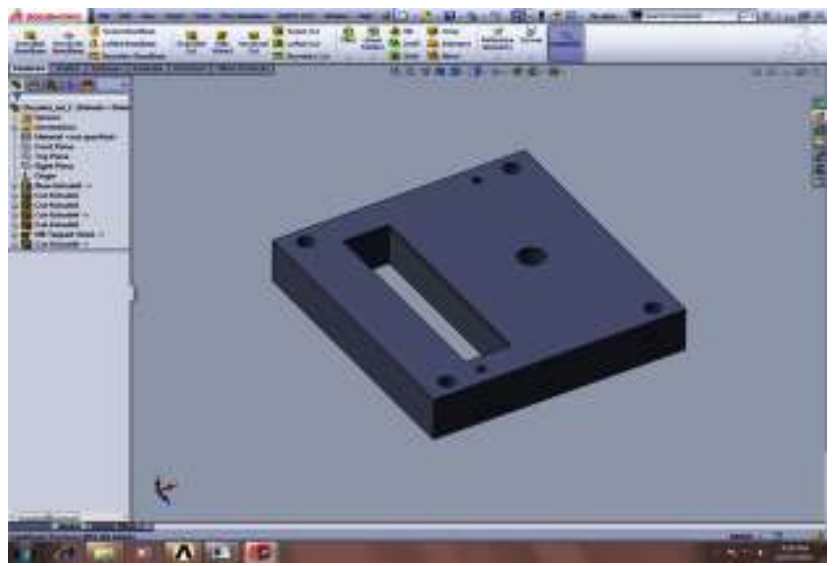

Figure 3: Computer Aided Design of Die Plate

Table 1: Component Data of Die Plate

\begin{tabular}{|l|l|}
\hline Material Properties & Die Plate \\
\hline Material & $\mathrm{HcHCr}$ \\
\hline Modulus of Elasticity, E & $2 * 10^{5} \mathrm{~N} / \mathrm{mm}^{2}$ \\
\hline Dimensions & $110^{*} 116 \mathrm{~mm}$ \\
\hline Cutting Force & $93000.96 \mathrm{~N}$ \\
\hline Thickness & $25 \mathrm{~mm}$ \\
\hline Type of Beam & Fixed Supported Beam \\
\hline
\end{tabular}

\section{Setup and Result Generation through Meshed Model}

Free meshed model of various components of press tool helped predicting various results such as stress, strain and deformation. These results can be used for validation in accordance with the theoretically calculated values of stress, strain and deformation. The basic procedure involves setting the directory or specifying the file name where the component (mesh file) will be saved.

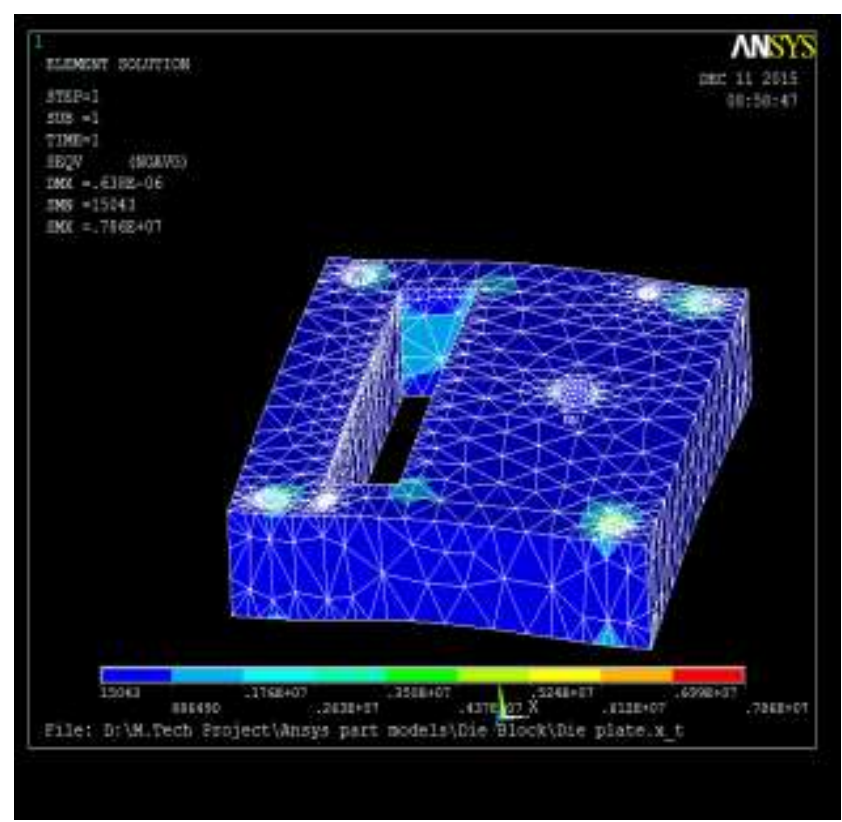

Figure 4: Meshed Model depicting stress and deformation in Die plate

Material properties taken into account for the Die plate block consist of modulus of elasticity, Poisson's ratio and density of the material.

Table 2: Material properties of die plate block

\begin{tabular}{|c|c|}
\hline Material Properties & Die Plate $(\mathrm{HcHCr})$ \\
\hline Modulus of elasticity, E & $2 * 10^{5} \mathrm{MN} / \mathrm{m}^{2}$ \\
\hline Poisson's Ratio & 0.33 \\
\hline Density & $7850 \mathrm{Kg} / \mathrm{m}^{3}$ \\
\hline Element Type & Solid- 20 node 95 \\
\hline Pressure & $93000.96 \mathrm{~N} / \mathrm{mm} 2$ \\
\hline
\end{tabular}

Table 3: Design Parameters

\begin{tabular}{|c|c|c|c|c|}
\hline SET & $\begin{array}{c}\text { Cutting Force } \\
(\text { Tones })\end{array}$ & $\begin{array}{c}\text { Stress } \\
(\text { N/mm2 })\end{array}$ & Strain & $\begin{array}{c}\text { Deformation } \\
(\mathrm{mm})\end{array}$ \\
\hline SET-1 & 14.22 & 7.86 & 0.000541 & 0.006381 \\
\hline SET-1 & 15.22 & 8.41 & 0.000579 & 0.00683 \\
\hline SET-1 & 16.22 & 8.92 & 0.000614 & 0.00715 \\
\hline SET-2 & 14.22 & 5.59 & 0.00039 & 0.00625 \\
\hline SET-2 & 15.22 & 5.598 & 0.000417 & 0.00669 \\
\hline SET-2 & 16.22 & 6.37 & 0.000444 & 0.00714 \\
\hline SET-3 & 14.22 & 6.04 & 0.000418 & 0.00604 \\
\hline SET-3 & 15.22 & 6.46 & 0.000448 & 0.00679 \\
\hline SET-3 & 16.22 & 6.89 & 0.000477 & 0.00723 \\
\hline SET-4 & 14.22 & 5.98 & 0.000414 & 0.00634 \\
\hline SET-4 & 15.22 & 6.4 & 0.000443 & 0.0064 \\
\hline SET-4 & 16.22 & 6.82 & 0.000472 & 0.00723 \\
\hline
\end{tabular}

To optimize the performance of a press tool design, different ranges of design parameters is proposed in Table 4 to optimize the performance of progressive press tool.

Table 4: Setting Model Parameters

\begin{tabular}{|c|c|c|}
\hline Set & $\begin{array}{c}\text { Thickness } \\
(\mathrm{mm})\end{array}$ & Die Clearance $(\mathrm{mm} /$ side $)$ \\
\hline SET-1 & 1.5 & 0.009 \\
\hline SET-2 & 1.6 & 0.096 \\
\hline SET-3 & 1.7 & 0.102 \\
\hline SET-4 & 1.8 & 0.108 \\
\hline
\end{tabular}




\section{International Journal of Science and Research (IJSR) \\ ISSN (Online): 2319-7064}

Index Copernicus Value (2013): 6.14 | Impact Factor (2014): 5.611

Finally, computational results obtained from two application examples with different design parameters by the use of ANSYS and Cutting force are presented for the further analysis of the mechanical system. This allows for predicting the influence of design parameter changes, in order to minimize stresses, strain, and deformation. Table 5 shows the analytical results for the press tool design.

Table 5: ANSYS Generated Results

\begin{tabular}{|c|c|c|c|c|}
\hline SET & $\begin{array}{c}\text { Cutting Force } \\
(\text { Tones })\end{array}$ & $\begin{array}{c}\text { Stress } \\
(\mathrm{N} / \mathrm{mm} 2)\end{array}$ & Strain & $\begin{array}{c}\text { Deformation } \\
(\mathrm{mm})\end{array}$ \\
\hline SET-1 & 14.22 & 7.86 & 0.000541 & 0.006381 \\
\hline SET-1 & 15.22 & 8.41 & 0.000579 & 0.00683 \\
\hline SET-1 & 16.22 & 8.92 & 0.000614 & 0.00715 \\
\hline SET-2 & 14.22 & 5.59 & 0.000390 & 0.00625 \\
\hline SET-2 & 15.22 & 5.598 & 0.000417 & 0.00669 \\
\hline SET-2 & 16.22 & 6.37 & 0.000444 & 0.00714 \\
\hline SET-3 & 14.22 & 6.04 & 0.000418 & 0.00604 \\
\hline SET-3 & 15.22 & 6.46 & 0.000448 & 0.00679 \\
\hline SET-3 & 16.22 & 6.89 & 0.000477 & 0.00723 \\
\hline SET-4 & 14.22 & 5.98 & 0.000414 & 0.00634 \\
\hline SET-4 & 15.22 & 6.40 & 0.000443 & 0.00640 \\
\hline SET-4 & 16.22 & 6.82 & 0.000472 & 0.00723 \\
\hline
\end{tabular}

\section{Design Parameter Optimization}

Usually the design process is treated as an optimization problem. To each user specified performance requirement is associated a performance index whose value increases with its level of violation. The stress, strain and deformation are considered as input and the outputs are design parameters and cutting force. The data from Table are used to build the $\mathrm{NN}$ - model.

Table 6: Setting simulation model parameters

\begin{tabular}{|c|c|c|c|c|c|}
\hline \multicolumn{3}{|c|}{ Input Data } & \multicolumn{3}{c|}{ Output Data } \\
\hline $\begin{array}{c}\text { Stress } \\
(\mathrm{N} / \mathrm{mm} 2)\end{array}$ & Strain & $\begin{array}{c}\text { Deformation } \\
(\mathrm{mm})\end{array}$ & $\begin{array}{c}\text { Cutting } \\
\text { Force } \\
\text { (Tones })\end{array}$ & $\begin{array}{c}\text { Thickness } \\
(\mathrm{mm})\end{array}$ & $\begin{array}{l}\text { Clearance } \\
(\mathrm{mm} / \mathrm{side})\end{array}$ \\
\hline 7.86 & 0.000541 & 0.006381 & 14.22 & 1.5 & 0.009 \\
\hline 8.41 & 0.000579 & 0.00683 & 15.22 & 1.5 & 0.009 \\
\hline 8.92 & 0.000614 & 0.00715 & 16.22 & 1.5 & 0.009 \\
\hline 5.59 & 0.000390 & 0.00625 & 14.22 & 1.6 & 0.096 \\
\hline 5.598 & 0.000417 & 0.00669 & 15.22 & 1.6 & 0.096 \\
\hline 6.37 & 0.000444 & 0.00714 & 16.22 & 1.6 & 0.096 \\
\hline 6.04 & 0.000418 & 0.00604 & 14.22 & 1.7 & 0.102 \\
\hline 6.46 & 0.000448 & 0.00679 & 15.22 & 1.7 & 0.102 \\
\hline 6.89 & 0.000477 & 0.00723 & 16.22 & 1.7 & 0.102 \\
\hline 5.98 & 0.000414 & 0.00634 & 14.22 & 1.8 & 0.108 \\
\hline 6.40 & 0.000443 & 0.00640 & 15.22 & 1.8 & 0.108 \\
\hline 6.82 & 0.000472 & 0.00723 & 16.22 & 1.8 & 0.108 \\
\hline
\end{tabular}

Figure 6 shows the results of comparative designs parameters and cutting force with those obtained with the ANSYS Model to the NN optimization. The response of the system to the input using the neural network is really good. If it is compared with the output from the ANSYS Model, there are some differences between them, but the two outputs are really near in almost all points and at peak values of the ANSYS results are also optimized in neural networks. So, this shows that is possible to simulate this system with a dynamic neural network, but the results are really dependent from the hidden layers, the number of neurons in each and the number of epochs.

Table 7: ANSYS and Neural network generated stress values

\begin{tabular}{|c|c|}
\hline \multicolumn{2}{|c|}{ STRESS (N/mm2) } \\
\hline Ansys & Neural Network \\
\hline 7.86 & 5.6571 \\
\hline 8.41 & 6.4377 \\
\hline 8.92 & 6.0825 \\
\hline 5.59 & 5.8108 \\
\hline 5.598 & 6.3536 \\
\hline 6.37 & 6.6909 \\
\hline 6.04 & 6.2487 \\
\hline 6.46 & 6.33 \\
\hline 6.89 & 6.99 \\
\hline 5.98 & 6.5627 \\
\hline 6.4 & 6.4123 \\
\hline 6.82 & 6.7413 \\
\hline
\end{tabular}

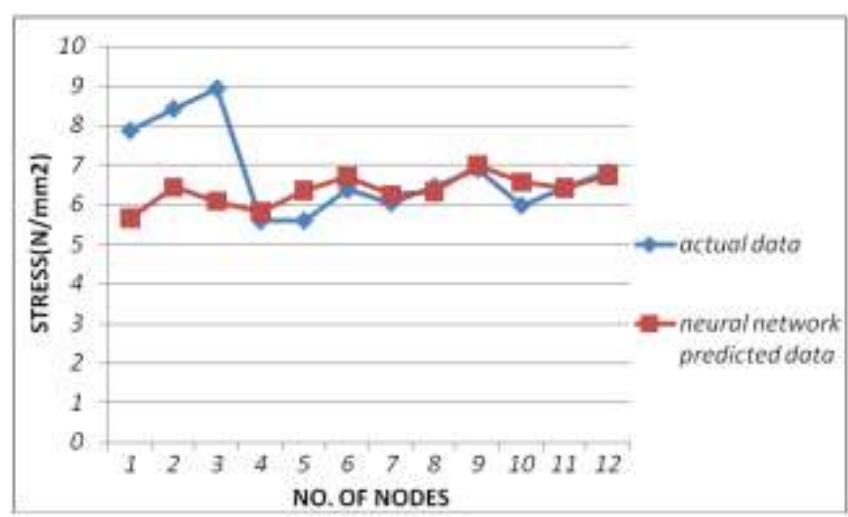

Figure 5: Stress Comparison based on Neural network generated data

Table 8: ANSYS and Neural network generated strain

\begin{tabular}{|c|c|}
\hline \multicolumn{2}{|c|}{ STRAIN } \\
\hline ANSYS & NEURAL NETWORK \\
\hline 0.000541 & 0.00049792 \\
\hline 0.000579 & 0.00057444 \\
\hline 0.000614 & 0.00041891 \\
\hline 0.00039 & 0.00042357 \\
\hline 0.000417 & 0.00041677 \\
\hline 0.000444 & 0.00040344 \\
\hline 0.000418 & 0.00042011 \\
\hline 0.000448 & 0.00039645 \\
\hline 0.000477 & 0.000512 \\
\hline 0.000414 & 0.000509 \\
\hline 0.000443 & 0.0004489 \\
\hline 0.000472 & 0.0004658 \\
\hline
\end{tabular}

Figures 5 shows the results of comparative strain with those obtained with the ANSYS Model to the NN optimization. 


\section{International Journal of Science and Research (IJSR) \\ ISSN (Online): 2319-7064}

Index Copernicus Value (2013): 6.14 | Impact Factor (2014): 5.611

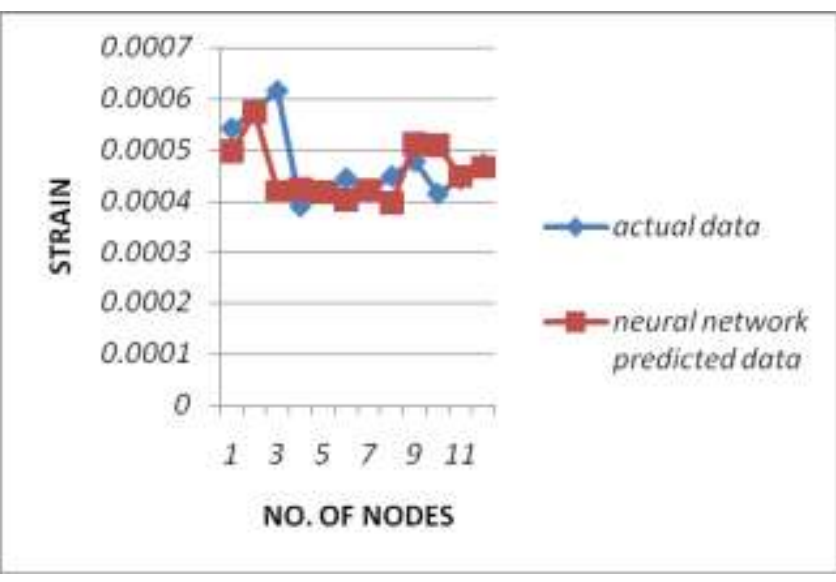

Figure 6: Strain Comparison based on neural network generated data

Table 9: ANSYS and Neural network generated deformation values

\begin{tabular}{|c|c|}
\hline \multicolumn{2}{|c|}{ DEFORMATION(mm) } \\
\hline Ansys & Neural Network \\
\hline 0.006381 & 0.0061706 \\
\hline 0.00683 & 0.006974 \\
\hline 0.00715 & 0.006105 \\
\hline 0.00625 & 0.0060508 \\
\hline 0.00669 & 0.0060679 \\
\hline 0.00714 & 0.0061377 \\
\hline 0.00604 & 0.0060566 \\
\hline 0.00679 & 0.0061743 \\
\hline 0.00723 & 0.006877 \\
\hline 0.00634 & 0.006415 \\
\hline 0.0064 & 0.0065 \\
\hline 0.00723 & 0.007199 \\
\hline
\end{tabular}

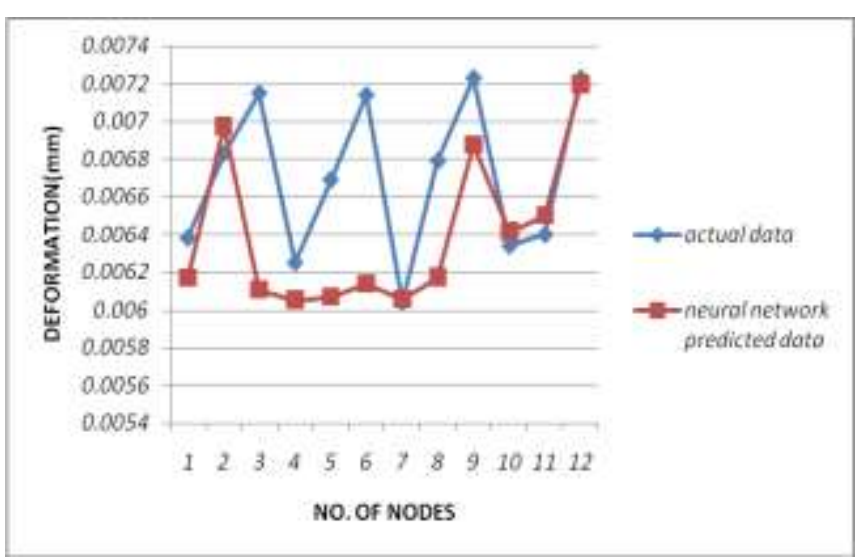

Figure 7: Deformation Comparison based on neural network generated data

Figure 7 shows the results of comparative deformation with those obtained with the ANSYS Model to the NN optimization. Based on the parameters generated by cascade forward backdrop propagation we have generated three different sets of design parameter graph to choose for a certain range of optimized die clearance and sheet metal thickness for a given cutting force
Table 10: ANSYS and Neural network generated clearance values

\begin{tabular}{|c|c|}
\hline \multicolumn{2}{|c|}{ DIE CLEARANCE (mm/side) } \\
\hline Ansys & Neural Network \\
\hline 0.009 & 0.095516 \\
\hline 0.009 & 0.088 \\
\hline 0.009 & 0.10704 \\
\hline 0.096 & 0.085105 \\
\hline 0.096 & 0.060232 \\
\hline 0.096 & 0.10359 \\
\hline 0.102 & 0.10653 \\
\hline 0.102 & 0.10218 \\
\hline 0.102 & 0.10315 \\
\hline 0.108 & 0.10523 \\
\hline 0.108 & 0.10599 \\
\hline 0.108 & 0.10788 \\
\hline
\end{tabular}

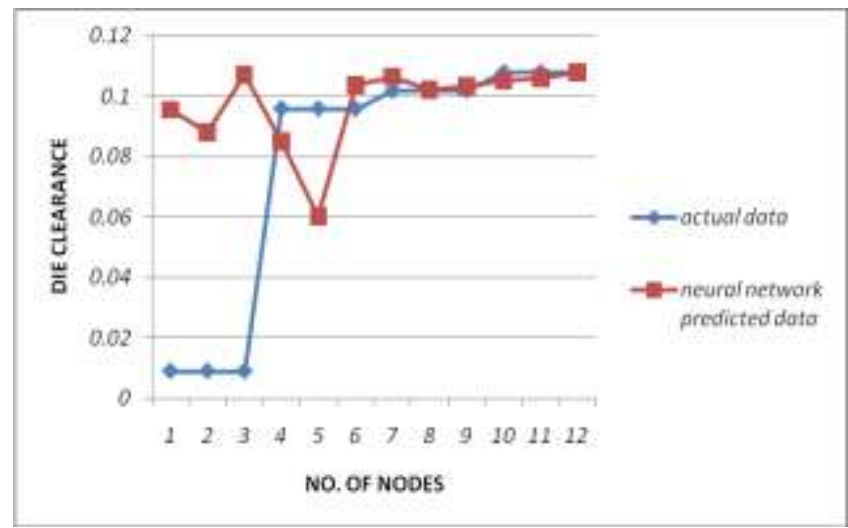

Figure 8: Die Clearance Comparison based on Neural network generated data

Figure 9 shows the results of comparative sheet metal thickness with those obtained with the ANSYS Model to the NN optimization

Table 11: ANSYS and Neural network generated thickness values

\begin{tabular}{|c|c|}
\hline \multicolumn{2}{|c|}{ Sheet Metal Thickness(mm) } \\
\hline Ansys & Neural Network \\
\hline 1.5 & 1.6353 \\
\hline 1.5 & 1.521 \\
\hline 1.5 & 1.674 \\
\hline 1.6 & 1.7849 \\
\hline 1.6 & 1.7849 \\
\hline 1.6 & 1.6778 \\
\hline 1.7 & 1.7453 \\
\hline 1.7 & 1.6706 \\
\hline 1.7 & 1.7145 \\
\hline 1.8 & 1.7798 \\
\hline 1.8 & 1.8156 \\
\hline 1.8 & 1.8345 \\
\hline
\end{tabular}




\section{International Journal of Science and Research (IJSR) \\ ISSN (Online): 2319-7064}

Index Copernicus Value (2013): 6.14 | Impact Factor (2014): 5.611

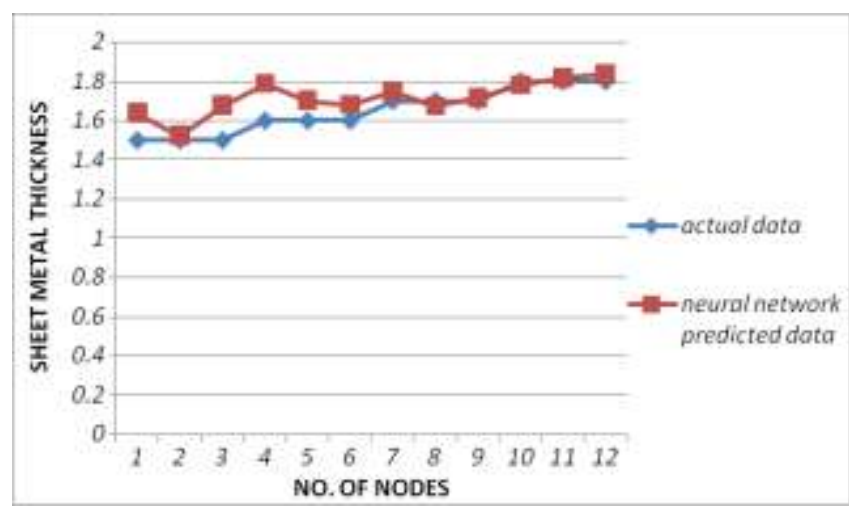

Figure 9: Sheet Metal Thickness Comparison based on Neural network generated data

Figure 10 shows the results of comparative cutting force with those obtained with the ANSYS Model to the NN optimization.

Table 12: ANSYS and Neural network generated force values

\begin{tabular}{|c|c|}
\hline \multicolumn{2}{|c|}{ Cutting Force (Tones) } \\
\hline Ansys & Neural Network \\
\hline 14.22 & 14.2273 \\
\hline 15.22 & 16.0204 \\
\hline 16.22 & 14.2522 \\
\hline 14.22 & 14.2371 \\
\hline 15.22 & 14.2233 \\
\hline 16.22 & 16.0992 \\
\hline 14.22 & 14.2274 \\
\hline 15.22 & 16.0757 \\
\hline 16.22 & 14.3533 \\
\hline 14.22 & 14.2221 \\
\hline 15.22 & 16.0861 \\
\hline 16.22 & 16.1001 \\
\hline
\end{tabular}

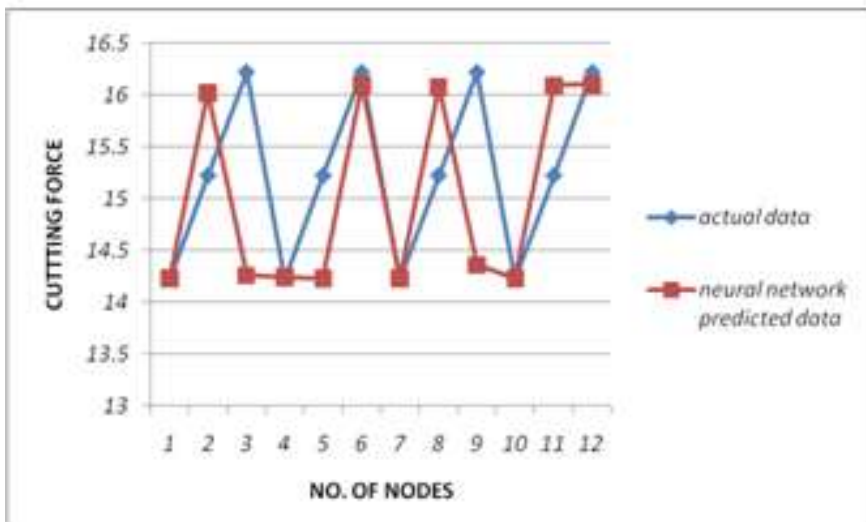

Figure 10: Cutting Force Comparison based on neural network generated data

The values thereby generated helps to choose an appropriate and optimized set of design parameters as well as cutting force input which is being depicted in table given below.

Table 13: Optimized Design Parameters

\begin{tabular}{|c|c|c|}
\hline $\begin{array}{c}\text { Cutting Force } \\
\text { (Tones) }\end{array}$ & $\begin{array}{c}\text { Die Clearance } \\
(\mathrm{mm} / \mathrm{side})\end{array}$ & $\begin{array}{c}\text { Sheet Metal Thickness } \\
(\mathrm{mm})\end{array}$ \\
\hline 14.2552 & 0.10704 & 1.674 \\
\hline
\end{tabular}

In order to validate my optimized design parameters it is essential to collaborate these results with the results generated by ANSYS software. Stress is used as a key factor to validate these results. The stress generated by neural network is compared with the ANSYS generated results. The ANSYS Software was used to remodel the press tool design using the optimized design parameters. After feeding the new optimized design parameters and remodeling the press tool design using SOLIDWORKS we have obtained the following results as depicted in the figure below.

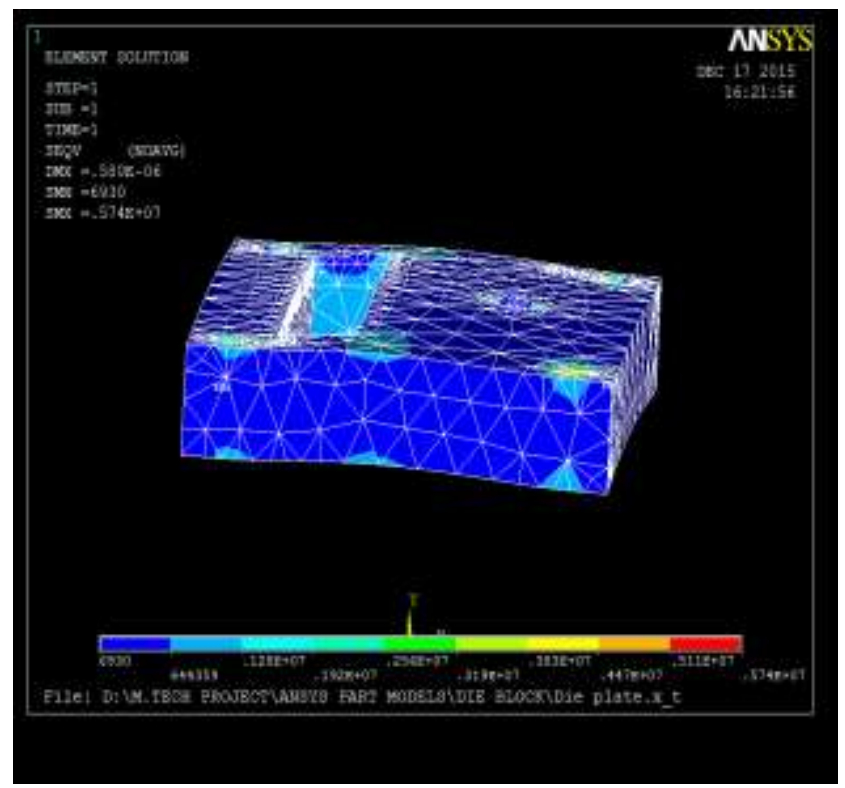

Figure 11: Remodeled \& optimized Die plate block

Value of stress is generated based on the finite element meshed model using ANSYS. This value of generated stress is compared with the neural network generated value of stress. This comparison proves that obtained design parameters based on neural network is optimized which concludes the project objective. The final comparison between the stress values generated is being depicted in the table below.

Table 14: Comparison of stress based on optimized design parameters

\begin{tabular}{|c|c|c|c|}
\hline \multicolumn{2}{|c|}{ Optimized Design Parameters } & \multicolumn{2}{c|}{ Stress (N/mm2) } \\
\hline $\begin{array}{c}\text { Die Clearance } \\
(\mathrm{mm} / \mathrm{side})\end{array}$ & $\begin{array}{c}\text { Sheet Metal } \\
\text { Thickness (mm) }\end{array}$ & $\begin{array}{c}\text { Neural Network } \\
\text { Based Result }\end{array}$ & $\begin{array}{c}\text { Ansys Based } \\
\text { Result }\end{array}$ \\
\hline 0.10704 & 1.674 & 6 & 5.74 \\
\hline
\end{tabular}

The above result can be further compared to the theoretical value of clearance and stress generated by neural network in order to prove that optimized result is better as compared to the theoretical result to minimize the stress produced in die plate block. The table below present a comparison between theoretical value of clearance and optimized clearance for a given sheet metal thickness. 


\section{International Journal of Science and Research (IJSR) \\ ISSN (Online): 2319-7064}

Index Copernicus Value (2013): 6.14 | Impact Factor (2014): 5.611

Table 15: Comparison of theoretical and optimized stress (ANSYS)

\begin{tabular}{|c|c|c|c|c|}
\hline & Theoretical & Optimized & \multicolumn{2}{|c|}{ Stress (N/mm2) } \\
\hline $\begin{array}{c}\text { Sheet Metal } \\
\text { Thickness } \\
(\mathrm{mm})\end{array}$ & $\begin{array}{c}\text { Die } \\
\text { Clearance } \\
(\mathrm{mm} / \mathrm{side})\end{array}$ & $\begin{array}{c}\text { Die } \\
\text { Clearance } \\
(\mathrm{mm} / \mathrm{side})\end{array}$ & $\begin{array}{c}\text { Theoretical } \\
\text { Result }\end{array}$ & $\begin{array}{c}\text { Ansys } \\
\text { Based } \\
\text { Result }\end{array}$ \\
\hline 1.674 & 0.10044 & 0.10704 & 7.306 & 5.74 \\
\hline
\end{tabular}

\section{Conclusion}

The influence of the sheet metal thickness and die clearance of a progressive press tool was investigated in this study. This project prescribes a model investigating the effect of potential parameters influencing the piercing and blanking process and their interaction. The die clearance and thickness optimization is carried out by using CAD Modeling (SolidWorks), Finite Element Method (FEM) with ANSYS Package and Neural Network Simulation in order to achieve the intended model objectives. The NN-model was used to replace the computer simulation experiment as a cost-effective mathematical tool for optimizing the system performance. The use of the NN model allowed the prediction of the system's response at other design points with a significantly lower computational time and cost.. In addition to the use of the NN model for the prediction of the response at different design points, the scheme allows for the visualization of the trends of the response surfaces when the design variables are changed. The global results obtained from this study indicate that the model parameters of the mechanical system are quite sensitive to the cutting force. The method presented in this thesis can be utilized for optimizing the performance of mechanical systems with die clearances. By utilizing the NN-model, the computer simulation time can be significantly reduced, while the response of the system can be studied and optimized for a range of input design variables.

Thereby based on analysis by ANSYS software and optimization based on $\mathrm{NN}$ technique we have attained optimized result based on sheet metal thickness and die clearance. These results are validated using error found in NN optimization tool, MATLAB. The optimized results of sheet metal thickness and die clearance helps in achieving fewer amounts of deformation and stress produced in die plate. Value of stress is generated based on the finite element meshed model using ANSYS. This value of generated stress is compared with the neural network generated value of stress.

This comparison proves that obtained design parameters based on neural network is optimized which concludes the project objective. The results when further compared to the theoretical value of clearance and stress generated by neural network proves that optimized result is better as compared to the theoretical result to minimize the stress produced in die plate block.

\section{References}

[1] Md Inaithul Rehaman, P Satish Reddy, Matta Manoj, N.Guru Murthy," Design and Analysis of Progressive
Die for Chain Link Plate", International Journal of Science Engineering and Advance Technology, IJSEAT, Vol 2, Issue 11, ISSN 2321-6905 November2014.

[2] Ch.Mastanamma, K.Prasada Rao, Dr. M.Venkateswara Rao," Design and Analysis of Progressive Tool", International Journal of Engineering Research \& Technology (IJERT) Vol. 1 Issue 6, August - 2012 ISSN: 2278-0181.

[3] Cyril Donaldson, George H LeCain, V C Goold, Tool design 3rd edition, Tata McGraw-Hill Education, New Delhi.

[4] Jyothi Bhaskar, G Sathya Prakash," Die design and analysis of progressive tool for can lid lever", IJREAT International Journal of Research in Engineering \& Advanced Technology, Volume 1, Issue 4, Aug-Sept, 2013 ISSN: $2320-8791$.

[5] S.K. Maiti," A numerical study on the edge-profile during shearing of bars using the principles of linear elastic fracture mechanics", J. Mech. Design, Trans. ASME 104 (1982) 661-665.

[6] M. Adachi et al., "Integrated CAD system for progressive dies", Fujitsu Scientific and Technical Journal, Vol. 19(2), pp.133-148, 1983.

[7] A. Ghosh, V. Raghuraman, P.B. Popat, "A new approach to mechanics of blanking operations: theoretical model and experimental verification", J. Mech. Working Technol. 11 (1985) 215- 228.

[8] K. Shirai and H. Murakami, "Development of a CAD/CAM system for progressive dies", Annals of the CIRP, Vol. 34, pp. 187-190, 1985.

[9] U.P. Singh, H.J.J. Kals, A.H. Streppel, "Computer aided design study of a die-set for punching blanking", in: Proceedings of the 28th International Machine Tool Design and Research Conference, Manchester, Macmillan, London, 1990, pp. 379-386.

[10]M. R. Duffy and Q. Sun, "Knowledge-based design of progressive stamping dies", Journal of Materials Processing Technology, Vol. 28, pp. 221-227, 1991.

[11] M. R. Duffy and Q. Sun, "Knowledge-based design of progressive stamping dies", Journal of Materials Processing Technology, Vol. 28, pp. 221-227, 1991.

[12] Y. K. D. V. Prasad and S. Somasundaram, "CADDS: An automated die design system for sheet metal blanking", Computing and Control Engineering Journal, Vol. 3, pp. 185-191, 1992.

[13]Y.K.D.V. Prasad, "Some studies on problems associated with automated design of cutting dies for sheet metal", Ph D Thesis, Department of Mechanical Engineering, Indian Institute of Technology, Bombay, India, 1992.

[14]U.P. Singh, A.H. Streppel, H.J.J. Kals, "Design study of the geometry of a punching/blanking tool", J. Mater. Process. Technol. 33 (1992) 331-345.

[15]B. T. Cheok et al., "Some aspects of a knowledge based approach for automating progressive metal stamping die design", Computers in Industry, Vol. 24, pp. 81-96, 1994.

[16]H. S. Ismail et al., "An intelligent object-oriented approach to the design and assembly of press tools", Annals of the CIRP, Vol. 44, pp. 91-96, 1995. 


\section{International Journal of Science and Research (IJSR) \\ ISSN (Online): 2319-7064}

Index Copernicus Value (2013): 6.14 | Impact Factor (2014): 5.611

[17] C.M. Choy, R. Balendra, "Simulation of the effect of the tool geometry changes on blanking operations", in: Proceedings of the Ninth International Cold Forming Congress, Paper 25, Solihull, UK, 1995.

[18] C.M. Choy, R. Balendra, "The influence of tool geometry on blanking characteristics", in: Proceedings of the Third International Conference on CIM, Singapore, 1995.

[19]K. Huang et al., "Automated design of progressive dies", Proc. Institution of Mechanical Engineers, Part B: Journal of Engineering Manufacture, Vol. 210, pp. 367376, 1996.

[20]E. Taupin, J. Breitlin, W. Wie-Tsu, T. Altan, "Material fracture and burr formation in blanking, results of FEM simulation and comparison with experiments", J. Mater. Process. Technol. 59 (1996) 68-78.

[21] T.C. Lee, L.C. Chan, P.F. Zeng, “Application of finite element deformation method in the fine blanking process", J. Mater. Process. Technol. 63 (1997) 744749.

[22]F.F aura, A. Garcia and M. Estrems, (1998), "Finite element analysis of optimum clearance in the blanking process". Journal of Materials Processing Technology, Vol.80-81, Page no.121-125.

[23]D. Brokken, W.A.M. Brekelmans, F.P.T. Baaijens, "Numerical modeling of the metal blanking process", J. Mater. Process. Technol. 83 (1998) 192-199.

[24]H. Samuel, "FEM simulation and experimental analysis of parameters of influence in the blanking process", J. Mater. Process. Technol. 84 (1998) 97-106.

[25] R. Singh and G. S. Sekhon, "A knowledge base system for the optimal selection of cutting clearance of die set", Proc. 11th ISME conference, IIT Delhi, 3-5 February 1999, pp. 605-611.

[26] A.A. Ambekar, "Analysis of blanking/punching for miniaturized components", M.Tech. Dissertation, Mechanical Engineering Department, IIT Bombay, Mumbai 400076, India, January 1999.

[27] S. Maiti, A. Ambekar, U. Singh, P. Date, and K. Narasimhan, "Assessment of influence of some process parameters on sheet metal blanking". Journal of Materials Processing Technology, Vol. 102, 2000, 249256. 